\title{
Article \\ Effect of Build Orientation on the Microstructure, Mechanical and Corrosion Properties of a Biodegradable High Manganese Steel Processed by Laser Powder Bed Fusion
}

\author{
Martin Otto ${ }^{1, *}$, Stefan Pilz ${ }^{1}\left(\mathbb{D}\right.$, Annett Gebert ${ }^{1}$, Uta Kühn ${ }^{1}$ and Julia Hufenbach ${ }^{1,2}$ \\ 1 Institute for Complex Materials, Leibniz IFW Dresden, Helmholtzstraße 20, 01069 Dresden, Germany; \\ s.pilz@ifw-dresden.de (S.P.); a.gebert@ifw-dresden.de (A.G.); u.kuehn@ifw-dresden.de (U.K.); \\ j.k.hufenbach@ifw-dresden.de (J.H.) \\ 2 Institute of Materials Science, TU Bergakademie Freiberg, Gustav-Zeuner-Str. 5, 09599 Freiberg, Germany \\ * Correspondence: m.otto@ifw-dresden.de; Tel.: +49-3514659608
}

Citation: Otto, M.; Pilz, S.; Gebert, A.; Kühn, U.; Hufenbach, J. Effect of Build Orientation on the

Microstructure, Mechanical and

Corrosion Properties of a

Biodegradable High Manganese Steel

Processed by Laser Powder Bed

Fusion. Metals 2021, 11, 944.

https://doi.org/10.3390/

met11060944

Academic Editor: Sandra

Carolina Cifuentes Cuéllar

Received: 7 May 2021

Accepted: 7 June 2021

Published: 10 June 2021

Publisher's Note: MDPI stays neutral with regard to jurisdictional claims in published maps and institutional affiliations.

Copyright: (c) 2021 by the authors. Licensee MDPI, Basel, Switzerland. This article is an open access article distributed under the terms and conditions of the Creative Commons Attribution (CC BY) license (https:// creativecommons.org/licenses/by/ $4.0 /)$

\begin{abstract}
In the last decade, additive manufacturing technologies like laser powder bed fusion (LPBF) have emerged strongly. However, the process characteristics involving layer-wise build-up of the part and the occurring high, directional thermal gradient result in significant changes of the microstructure and the related properties compared to traditionally fabricated materials. This study presents the influence of the build direction (BD) on the microstructure and resulting properties of a novel austenitic Fe-30Mn-1C-0.02S alloy processed via LPBF. The fabricated samples display a $\{011\}$ texture in $\mathrm{BD}$ which was detected by electron backscatter diffraction. Furthermore, isolated binding defects could be observed between the layers. Quasi-static tensile and compression tests displayed that the yield, ultimate tensile as well as the compressive yield strength are significantly higher for samples which were built with their longitudinal axis perpendicular to BD compared to their parallel counterparts. This was predominantly ascribed to the less severe effects of the sharp-edged binding defects loaded perpendicular to BD. Additionally, a change of the Young's modulus in dependence of BD could be demonstrated, which is explained by the respective texture. Potentiodynamic polarization tests conducted in a simulated body fluid revealed only slight differences of the corrosion properties in dependence of the build design.
\end{abstract}

Keywords: iron alloys; biodegradable metals; laser powder bed fusion; microstructure; mechanical properties; corrosion behaviour

\section{Introduction}

Additive manufacturing (AM) opens up new possibilities to fabricate load-adapted implants with a high freedom of design out of metallic biomaterials. This is possible due to the layer-wise manufacturing, which also enables function integration [1-4]. Especially laser powder bed fusion (LPBF; also known as selective laser melting, SLM) shows a large potential for the fabrication of customized implants.

In the LPBF process high cooling rates arise, starting from the molten state. Therefore, specific non-equilibrium microstructural effects can be realized, e.g., grain refinement, extended solid solubility promoting the reduction of phase segregation size and the fraction or even full suppression of secondary phase precipitation. Such effects can be very beneficial for the resulting mechanical and chemical properties. Thus, LPBF offers a great potential for the manufacturing of load-adapted degradable implants with tailored microstructures. Nevertheless, the usually large temperature gradient in close vicinity of the laser melt track results in a rather directional solidification out of which elongated grains and crystallographic anisotropy, respectively defined as texture, may occur. Together with the specific defects of the layer-by-layer manufacturing such as inclusions, porosity and residual stresses, this may result in multi-scale microstructural anisotropy characteristics. 
By process control, e.g., with adapted scan strategies or application of a substrate plate heating, the microstructure can be tailored for different grain morphologies, textures and phase compositions and the defect formation can be reduced [5]. Such anisotropy effects of LPBF specimens will not only yield mechanical properties which are dependent on the build orientation, but might impact the corrosion behaviour as well [6]. This can be traced back to the fact that in polycrystalline metals the grain size and the crystallographic orientation are known to influence corrosion reactions through the surface energy, dissolution, adsorption and oxidation characteristics of the exposed grains [7-9]. Therefore, the correlated anisotropic material behaviour has to be considered for potential applications.

LPBF has been intensively used for several non-degradable, metallic biomaterials, such as Ti-based or CoCr-based alloys, AISI 316L steel as well as noble metal, shape memory or bulk metallic glass alloys [10-19]. However, for the processing of biodegradable metals and alloys based on $\mathrm{Mg}$, Zn, or Fe via LPBF there are only a limited number of studies published $[15,20,21]$. Among the biodegradable alloys, manganese steels are very promising due to their suitability for LPBF processability. Their adjustable strength and ductility, high integrity during degradation over several months and adequate biocompatibility make them promising for stent applications as it has been shown by various authors $[20,22-28]$. Especially, the mechanical properties of these iron manganese alloys can be tailored to be in the range of those of the clinically applied 316L. This non-degradable steel is often utilized as a reference material for the development of novel Fe-based stent materials [29-31].

In previous studies the presented Fe-30Mn-1C-0.02S (FeMnCS) alloy was analysed in the as-cast state and showed already an attractive combination of mechanical properties, corrosion rates in various synthetic body fluids and cell compatibility [27,32]. However, to meet the requirements for implant applications, further studies with the aim to obtain a more homogenous degradation, as well as further enhanced mechanical properties were performed. Therefore, the FeMnCS alloy was recently processed by LPBF. This resulted in a significantly refined microstructure, therefore improved yield and ultimate strengths under tensile and compressive load along with a less localized, slightly decreased corrosion rate due to suppression of $\mathrm{MnS}$ precipitates [33]. Anyhow, the dependence of microstructural features and resulting properties of LPBF fabricated biodegradable parts on the build direction (BD) has not been intensively examined yet, but is of high relevance for later application.

In this study the influence of the build direction (BD) on the microstructure, the mechanical and the corrosion properties were investigated for a LPBF-processed FeMnCS steel. Therefore, the grain morphology and grain orientation were analysed for specimens with their longitudinal axis being parallel or perpendicular to the BD. The resulting deformation and fracture behaviour under tensile and compressive load as well as the electrochemical corrosion behaviour in a physiological electrolyte were assessed comparatively.

\section{Materials and Methods}

The spherical FeMnCS powders used for the LPBF process were prepared by electrode induction melting gas atomization (EIGA; ECKART TLS GmbH, Bitterfeld-Wolfen, Germany, gas: Ar) and were subsequently sieved to a nominal particle size range of $15-45 \mu \mathrm{m}$ (mean particle size of $33 \mu \mathrm{m}$ ). The processing of the FeMnCS specimens was carried out with a SLM 250 HL device (SLM Solutions Group AG, Luebeck, Germany) equipped with a $400 \mathrm{~W}$ Yb:YAG laser. A meander scanning strategy with a layer thickness of $30 \mu \mathrm{m}$, laser power of $175 \mathrm{~W}$, scanning velocity of $700 \mathrm{~mm} / \mathrm{s}$, a hatch distance of $0.09 \mathrm{~mm}$ and an inter-layer rotation of $79^{\circ}$ was applied. The processing chamber of the device was flooded with Ar to reduce the oxygen content below $100 \mathrm{ppm}$. Inductively coupled plasma optical emission spectrometry (ICP-OES) was conducted for analyzing the Mn and Fe content (iCAP 6500 Duo View, Thermo Fisher Scientific Inc., Waltham, MA, USA). To analyze the $C$ and $S$ contents of the bulk material, carrier gas hot extraction (CGHE; EMIA 820V, HORIBA Europe GmbH, Oberursel, Germany) was employed. The chemical composition analysis 
data are summarized in Table 1 . They are in conformity with previous work and meet the nominal composition [33].

Table 1. Results of chemical composition analysis of the laser powder bed fusion (LPBF) bulk samples of Fe-30Mn-1C-0.02S (FeMnCS) in wt\%.

\begin{tabular}{cccc}
\hline Fe & Mn & C & S \\
\hline $67.9 \pm 0.18$ & $30.26 \pm 0.08$ & $0.991 \pm 0.007$ & $0.0159 \pm 0.0001$ \\
\hline
\end{tabular}

For microstructural analysis, compression tests, determination of Young's modulus and corrosion evaluation cubes with a side length of $8 \mathrm{~mm}$ were manufactured by LPBF. Out of these cubes the test samples were eroded by wire electrical discharge machining, whereas the sample planes for electron backscatter diffraction (EBSD) and corrosion analysis are denoted after the sample coordinate system in Figure 1 as Y-BD and X-Y, which are parallel and perpendicular to BD, respectively. Cylinders with a diameter of $7 \mathrm{~mm}$ and length of $42 \mathrm{~mm}$, were built either parallel or perpendicular to BD, out of which the tensile specimens were turned by an automated computerized numerical control machine. Ultrasonic measurements were performed for determination of precise Young's modulus values on plates with the EBSD sample geometry. The plane-parallel specimen surfaces were ground down to P4000 SiC paper before their thickness was measured with a precision micro screw gauge. A Transducer V222-BC-RM served for transversal and type 2012 for longitudinal wave velocity measurements in combination with a sending and receiving unit (Model 5900 PR, Olympus Europa SE \& Co. KG, Hamburg, Germany). The relative density was determined by the Archimedes method (CUBIS, Sartorius AG, Goettingen, Germany).

Parallel to BD

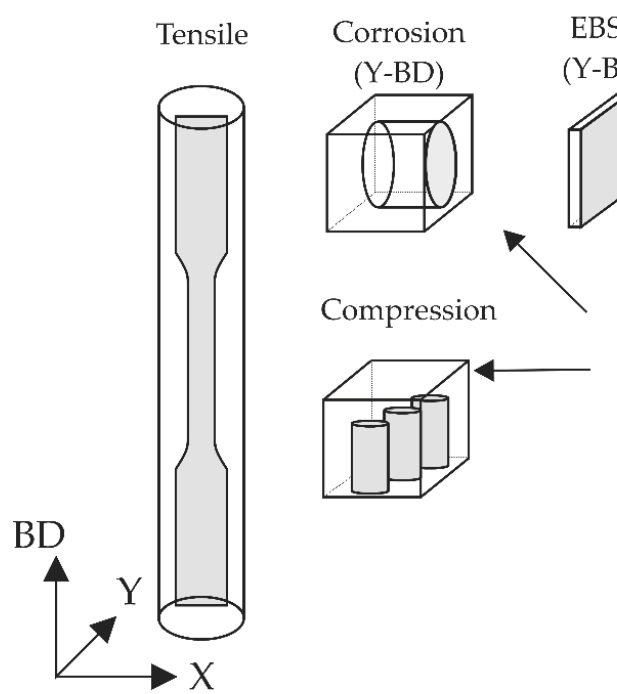

\section{Perpendicular to BD}
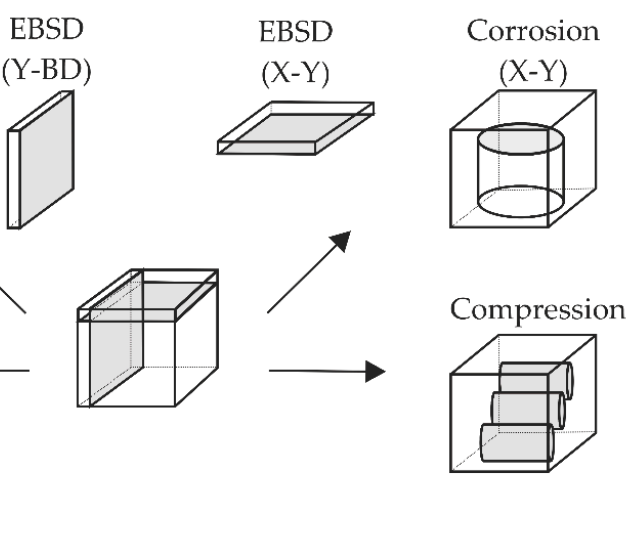

Tensile

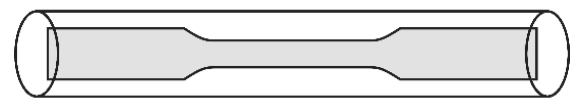

Figure 1. Coordinate system and test samples machined out of cubes and cylinder specimens arranged parallel and perpendicular to the build direction (BD) for quasi-static tensile and compression tests, electron backscatter diffraction (EBSD) analysis and potentiodynamic polarization measurements.

Microstructural features were investigated by scanning electron microscopy (SEM; Leo 1530 Gemini, Carl Zeiss AG, Oberkochen, Germany) combined with EBSD (e-Flash ${ }^{\text {HR }}$, Bruker Nano GmbH, Berlin, Germany). The samples for the SEM and EBSD analysis were first ground to $\mathrm{SiC}-\mathrm{P} 4000$ grit paper, subsequently polished down to $0.25 \mu \mathrm{m}$ diamond and finally polished with $0.02 \mu \mathrm{m}$ colloidal silica suspension (Mastermet 2, Buehler, Esslingen 
am Neckar, Germany). For grain size and texture determination at least three EBSD measurements per sample were performed, each covering an area of $2.4 \times 1.8 \mathrm{~mm}^{2}$ for the Y-BD section and $1.2 \times 0.9 \mathrm{~mm}^{2}$ for the $X-Y$ section. The used step sizes were $3 \mu \mathrm{m}$ and $0.75 \mu \mathrm{m}$ at a sample tilt of $70^{\circ}$, a working and detector distance of $16 \mathrm{~mm}$ and an acceleration voltage of $20 \mathrm{kV}$. The Matlab-toolbox MTEX v. 5.5 was used for data analysis [34]. The EBSD maps were post-processed by replacing "wild spikes", which are isolated mis-indexed points. Zero solutions were extrapolated if they were surrounded by a minimum of seven indexed nearest neighbours. A minimum grain boundary threshold of $15^{\circ}$ was chosen for grain detection, whereas grains smaller than four pixels were excluded from the grain size determination. The orientation density function (ODF) calculation was performed with a halfwidth of $5^{\circ}$. To evaluate the influence of the crystallographic texture on the Young's modulus, the orientation dependence of the elastic properties of the material was calculated based on the determined texture data [35].

Quasi-static room temperature compression and tensile tests were performed at a strain rate of $10^{-3} \mathrm{~s}^{-1}$ using a universal testing machine (8562, Instron GmbH, Darmstadt, Germany) for specimens with their long axis oriented parallel or perpendicular to the LPBFBD. For the compression tests, four cylindrical samples ( $3 \mathrm{~mm}$ in diameter, $6 \mathrm{~mm}$ in length) with plane-parallel surfaces were analysed. Under compression load, the samples showed no failure and were stopped at a strain of $25 \%$ due to bulging and therefore, multiaxial stress states. Tensile tests were performed with five round specimens (width of grip section: $4 \mathrm{~mm}$, inner width: $2 \mathrm{~mm}$, gauge length: $10 \mathrm{~mm}$, total length: $40 \mathrm{~mm}$ ) according to DIN 50125:2016-12 [36]. The compression and tensile test samples were machined out of the cubes and cylinders, respectively. This was done to minimize the impact of the LPBF surface for the mechanical tests.

Potentiodynamic polarization measurements were performed to test the corrosion behaviour in corrected simulated body fluid (c-SBF) solution buffered by Tris (hydroxymethyl)aminomethane (TRIS) at $37{ }^{\circ} \mathrm{C}$. The composition was prepared according to Kokubo and Takadama [37]. The electrochemical tests were performed in a three-electrode, double-wall glass cell connected to a potentiostat (1287A, AMETEK GmbH, Meerbusch, Germany). Alloy samples with a diameter of $7 \mathrm{~mm}$ were ground down to SiC-P4000, rinsed with ethanol, dried and employed as rotating disc working electrodes. A rotation velocity of $500 \mathrm{rpm}$ was used to simulate laminar flow conditions similar to blood flow. A saturated calomel electrode (SCE, E $=241 \mathrm{mV}$ vs. SHE) served as reference electrode and a large area $\mathrm{Pt}$ net as counter electrode. After stabilizing the open circuit potential (OCP) for $1 \mathrm{~h}$, a linear potentiodynamic polarization measurement was performed in a potential range from $-0.15 \mathrm{~V}$ vs. OCP to $1.5 \mathrm{~V}$ vs. SCE using a scan rate of $0.5 \mathrm{mV} \mathrm{s}^{-1}$. Each measurement was repeated at least four times to assess the reproducibility. Graphical extrapolation was employed to determine corrosion data like corrosion potential $\left(\mathrm{E}_{\mathrm{corr}}\right)$ and corrosion current density ( $\left.i_{\text {corr }}\right)$ from the semi-logarithmic i-E plots.

\section{Results and Discussion}

\subsection{Microstructure and Texture}

The microstructure of the LPBF-processed FeMnCS alloy exclusively consists of face centered cubic (fcc) austenite phase, in which the elements are homogenously distributed. This was already shown by EBSD, energy dispersive X-ray spectroscopy (EDX) and X-ray diffraction analysis in previous studies [33]. Representative EBSD orientation mappings of the cross and the longitudinal section of a LPBF-processed FeMnCS sample are displayed in Figure $2 \mathrm{a}, \mathrm{b}$ visualizing clear differences in the microstructure between the two inspection planes. For the longitudinal section large grains, elongated parallel to BD, can be observed which is indicated by the centric white arrow in Figure $2 b$ and the corresponding top view in Figure 2a. The mean equivalent circular diameter of the grains is around $77 \mu \mathrm{m}$. In contrast, a significantly smaller grain size of $47 \mu \mathrm{m}$ was determined for the $X-Y$ plane and the grain morphology can be described as a square or an equiaxed morphology. These observations are in accordance with our former findings and suggest a columnar grain 
growth parallel to the BD during the LPBF process [33]. Similar observations were reported by Köhnen et al. for an austenitic high manganese steel and similar scan parameters [38].

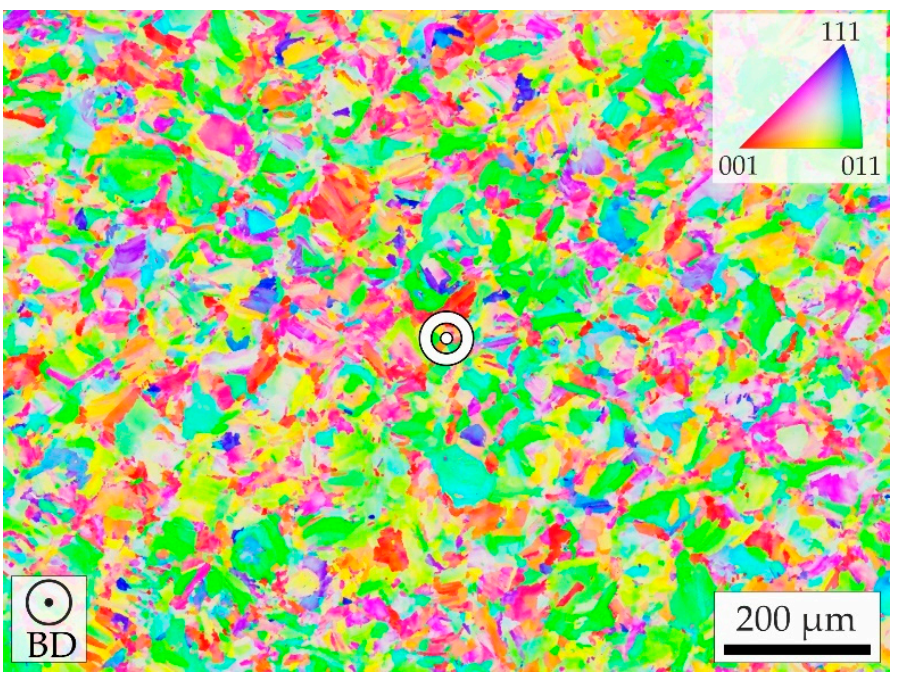

(a)

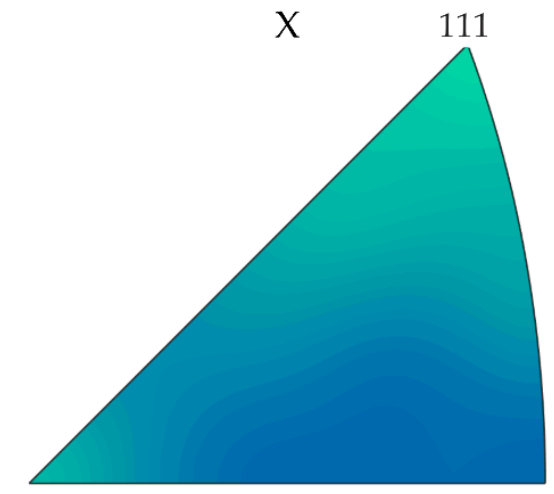

001

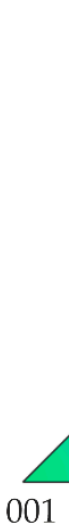

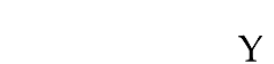

011001

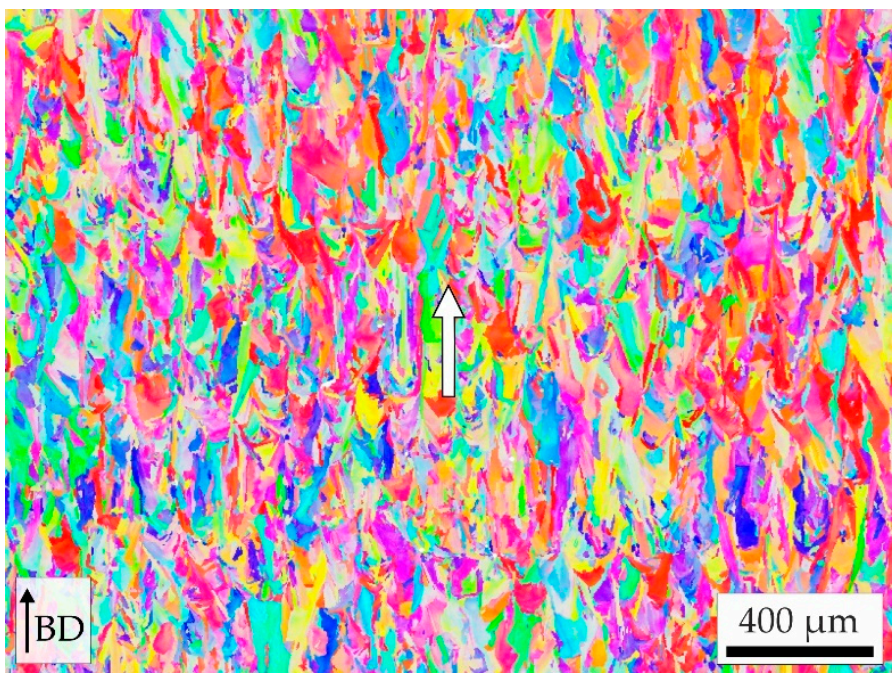

(b)
$Y$
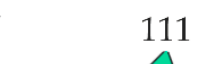

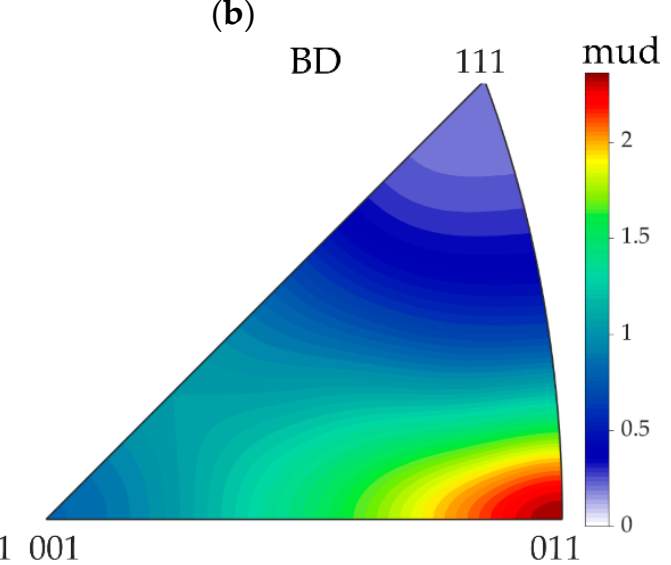

(c)

Figure 2. EBSD inverse pole figure (IPF) maps of sample planes (a) perpendicular to BD (X-Y), (b) parallel to BD (Y-BD) with the principal grain growth direction indicated by the centric white symbols, IPF color coding with respect to the sample surface, and (c) a representative IPF derived from an EBSD X-Y sample with the multiples of uniform distribution (mud) scale.

Also, distinct differences with respect to the crystallographic orientation are present for both sample planes, as can be seen from Figure 2a,b. Based on the EBSD data sets for the fcc austenite phase, the crystallographic orientations were visualized in relation to the sample coordinate system. Therefore, in the sample directions X, Y and BD inverse pole figures (IPF) have been calculated and are depicted in Figure 2c.

For the $\mathrm{X}-\mathrm{Y}$ plane, that means the section perpendicular to $\mathrm{BD}$, only a weak texture is present. For these sample directions the intensity of $\{011\}$ is slightly decreased (around 0.8 mud (multiples of uniform distribution)), whereas the intensity of $\{111\}$ and $\{001\}$ is slightly increased (around 1.4 mud). In BD the observed texture is more pronounced. A 2.5-fold increased intensity for $\{011\}$ was detected, which is besides the $\{001\}$ plane the favored crystallizing plane for cubic materials after 3d-solidification theory [39] and was verified for cubic LPBF-processed materials [40]. Another factor promoting such $\{011\}$ texture might derive from the solidification dependence on the melt pool geometry [41]. Furthermore, the intensity of $\{111\}$ is significantly weakened (0.2 mud). The amount and type of special low energy coincidence site lattice (CSL) grain boundaries were also analysed as they can have an impact on corrosion rates [42,43]. However, in this study no 
significant differences with respect to the different sample planes could be found for CSL boundaries.

For the LPBF manufactured FeMnCS alloy samples a typical relative density value of 99.4\% was determined. Distinct process related defects could be identified that were visible in the respective investigated sample planes. As exemplarily shown in Figure 3a, small pores of approximately $15 \mu \mathrm{m}$ in diameter were occasionally detectable in both inspection planes. In contrast, microstructure defects with sharp edges and crescent like form were only seen in the plane parallel to BD, indicated in Figure 3b. These defects can be defined as binding defects due to insufficient fusion of consecutive powder layers.

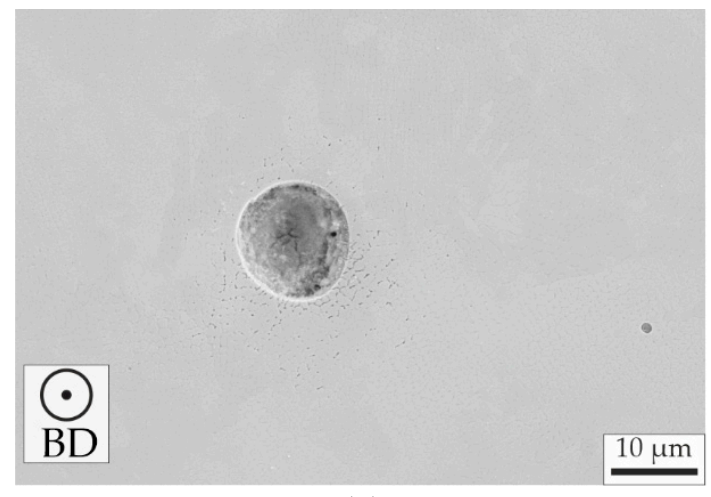

(a)

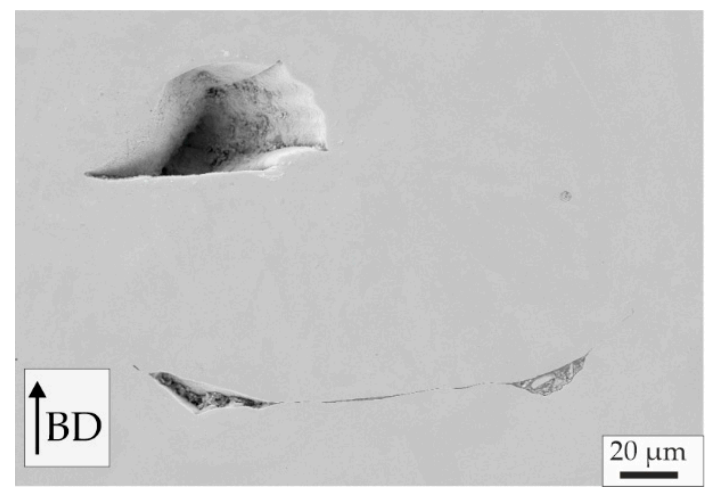

(b)

Figure 3. Typical LPBF defect types identified for the FeMnCS alloy with (a) small round-shaped entrapped gas pores and (b) sharp-edged crescent formed binding defects between consecutive LPBF layers.

The analysed differences of grain size and morphology, texture as well as defects may affect the mechanical and corrosion properties, which will be presented in the following sections.

\subsection{Mechanical Properties}

The mechanical properties of the LPBF samples with their long axis oriented parallel or perpendicular to BD are compared in Figure 4. The related determined average parameter values and their standard deviations are summarized in Table 2. The representative engineering stress-strain curves under quasi-static tensile load (Figure 4a) show a high yield strength above $550 \mathrm{MPa}$ followed by a uniform elongation up to fracture. Only minimal necking was observed. The serrations in the plastic deformation regime, starting at around $2.5 \%$ of total elongation, are results of the dynamic strain aging (DSA) of these alloys [44]. The DSA and the twinning-induced plasticity (TWIP) effect, which was already shown in previous studies [33], are characteristic features of FeMnC steels [45]. From Figure 4a and Table 2 superior mechanical properties from tensile samples fabricated perpendicular to $\mathrm{BD}$ are clearly visible. This trend was confirmed by the uniaxial compression tests that are visualized in Figure 4b.

These obtained differences in dependence of the sample orientation may derive directly from the LPBF process characteristics. The high strength values for LPBF-processed FeMnCS are in line with the high cooling rate and the resulting microstructural refinement. In addition the nature of melting and solidification phenomena during LPBF results in elongated grains and a pronounced texture in $\mathrm{BD}$. Additionally inter-layer binding defects between consecutive layers may arise when the energy density is locally not sufficient for proper layer fusion [46]. These, under partially molten powder particles, spatially extended imperfections are characterised by their crescent shaped cross section in the Y-BD plane and strict alignment parallel to the layers $[47,48]$, as shown in Figure $3 b$.

Their sharp edges can act as stress concentration sites when loaded orthogonal in tension, i.e., when getting pulled along the BD axis. Such defects also reduce the sample cross section and are especially severe-promoting premature failure even at high bulk 
densities-if they are accumulated in one layer with improper binding. In contrast, for the perpendicular to BD built tensile specimens these defects are less critical, because their sharp edges are aligned parallel to the load direction. This reduces their stress concentration impact. Consequently, the perpendicular to $\mathrm{BD}$ built tensile specimens offer a higher value of load-bearing, which is in line with the findings by Röttger et al. and Deev et al. [49,50]. The mechanical anisotropy might be therefore pronounced if the energy density was locally insufficient in the fusion of consecutive layers.

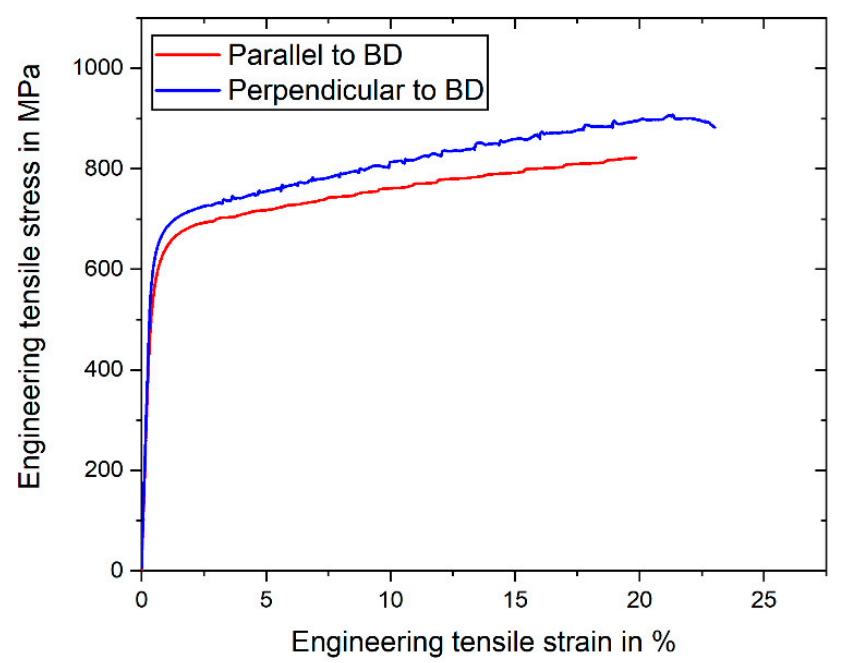

(a)

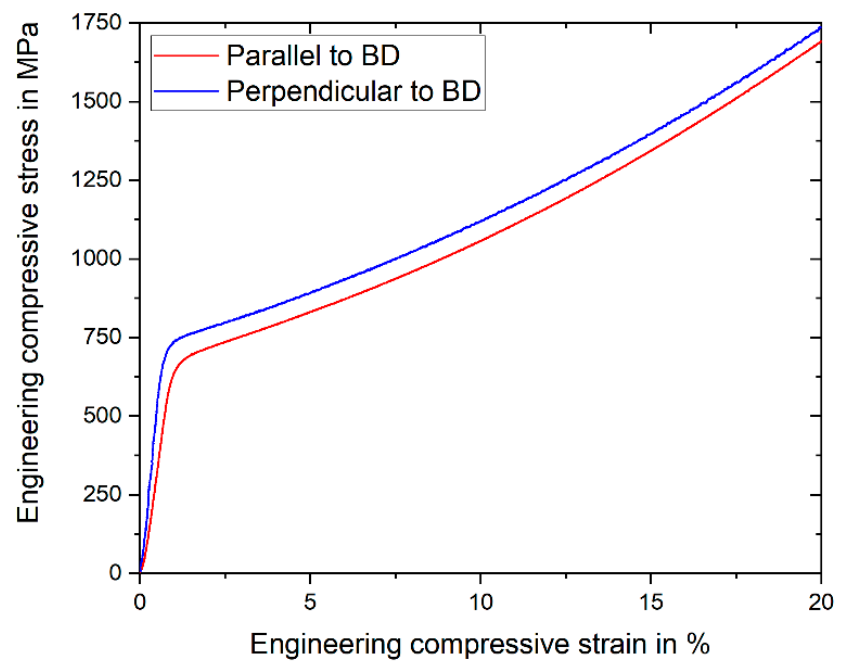

(b)

Figure 4. Representative tensile (a) and compressive (b) engineering stress-strain curves for specimens oriented with their longitudinal axis parallel and perpendicular to BD.

Table 2. Mechanical properties of LPBF samples oriented parallel or perpendicular to build direction (BD).

\begin{tabular}{ccc}
\hline & Parallel to BD & Perpendicular to BD \\
\hline Tensile yield strength, 0.2\% offset in MPa & $587 \pm 21$ & $640 \pm 11$ \\
Ultimate tensile strength in MPa & $803 \pm 54$ & $925 \pm 31$ \\
Total elongation in \% & $19.3 \pm 7.7$ & $22.5 \pm 3.1$ \\
Compressive yield strength, 0.2\% offset in $\mathrm{MPa}$ & $647 \pm 17$ & $704 \pm 18$ \\
\hline
\end{tabular}

In compression testing these inter-layer defects are less detrimental, which can be seen by the equal amount of standard deviation in the compressive yield strength (see Table 2). Nevertheless, the trend of higher strength values for the perpendicular built samples is similar to the tensile results. For perpendicular specimens the strained cross section corresponds to the EBSD Y-BD samples with a larger grain size than the $X-Y$ counterparts. After the Hall-Petch relation the larger grain size should result in less strengthening for the perpendicular specimens, which contradicts the overserved trend in strength. Thus, the remaining differences in compression strength might be attributed to the influence of texture as was stated by Charmi et al. [31].

Fracture surfaces of tensile test samples oriented parallel to BD, i.e., with the fracture surface in the X-Y plane, and perpendicular to BD (Y-BD plane) are shown in Figure 5a-f. For both sample orientations a mixed ductile and brittle fracture is visible, indicated by dimple and smooth surfaces, respectively. Several large brittle areas with a round shape (Figure 5c,e) reveal the premature failure for tensile samples built parallel to BD. In contrast, by comparing Figure $5 d, c$, elliptical defects are arranged in form of rows. Because of insufficient fusions of consecutive LPBF layers also several sharp-edged inter-layer binding defects (Figure 3b) can appear in such an arrangement. Under severe loading along their longitudinal axis they could act as crack initiation sites and result in brittle fracture areas 
as shown in Figure 5d,f. When loaded orthogonal, these inter-layer defects are even more critical and lead to premature failure greater. This trend confirms the findings of former research to the fracture of ductile materials processed by LPBF [50]. Therefore, the LPBF defects, depending on their distribution and shape in the sample, may have a significant impact on the mechanical properties.

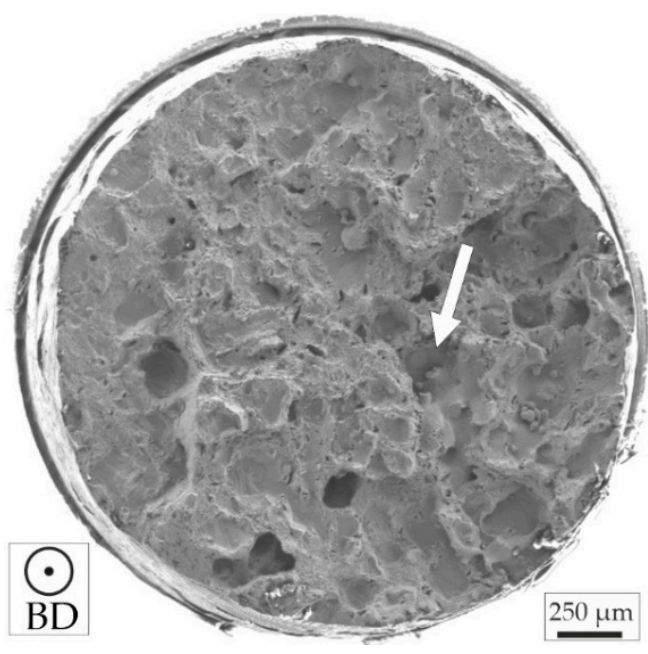

(a)

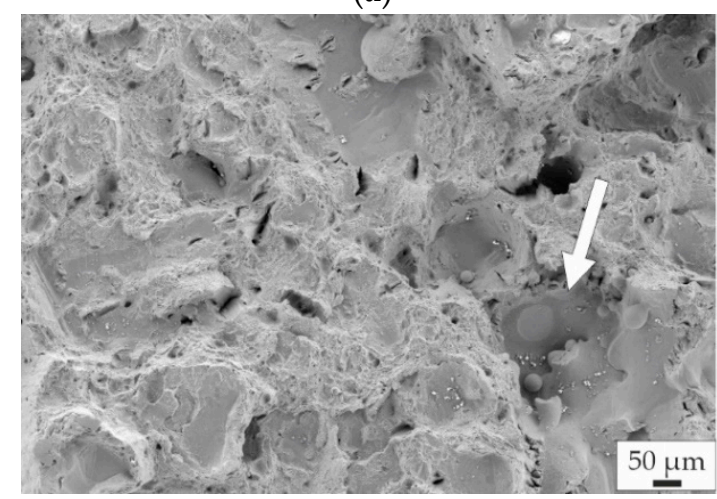

(c)

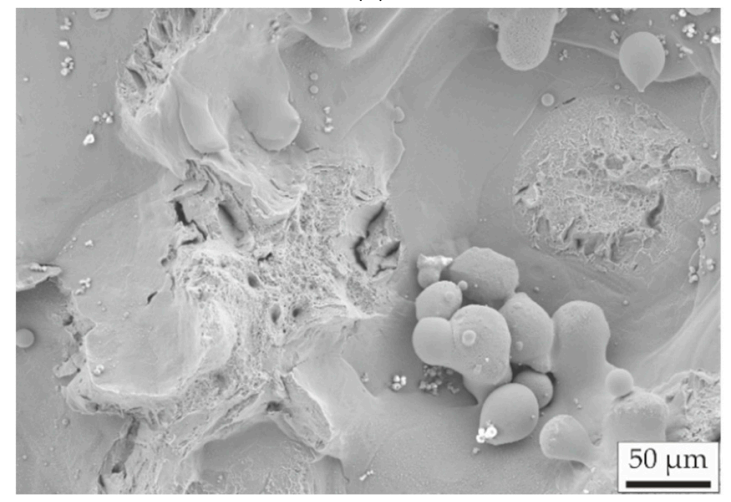

(e)

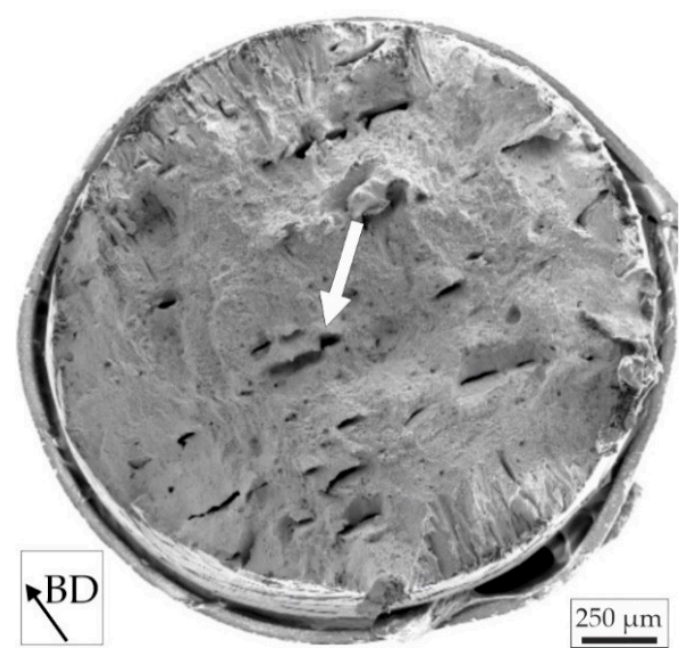

(b)

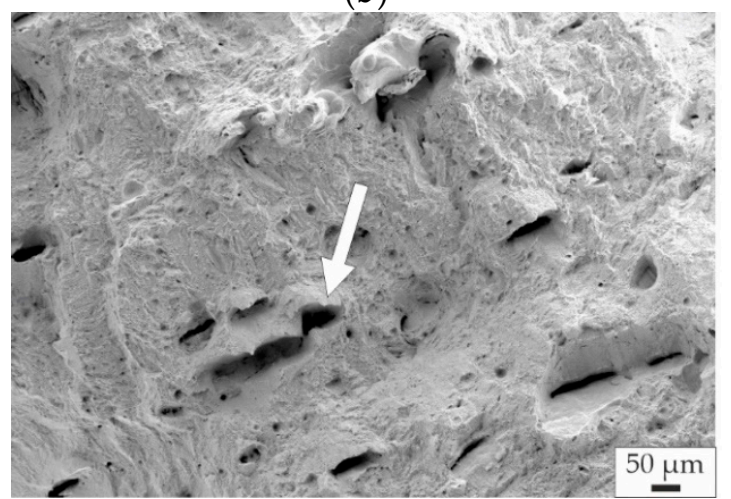

(d)

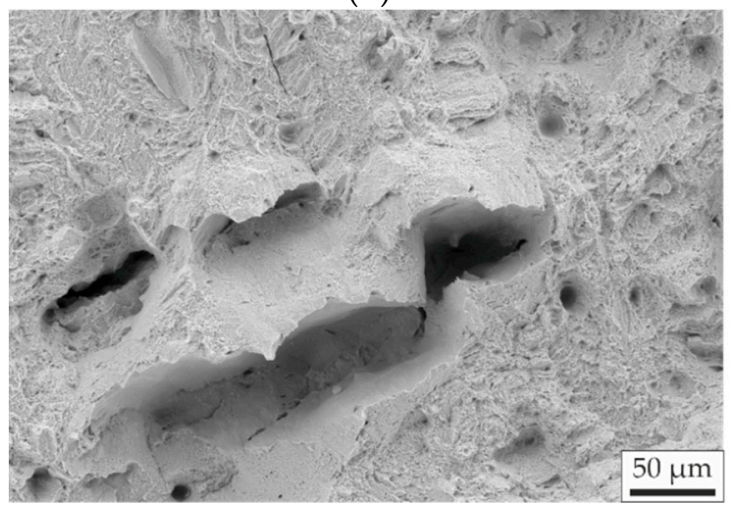

(f)

Figure 5. Fracture surfaces under different magnifications of tensile specimens tested parallel (a,c,e) and perpendicular $(\mathbf{b}, \mathbf{d}, \mathbf{f})$ to BD showing mixed ductile and brittle fracture. Representative defects indicated by white arrows in (a-d) are magnified in $(\mathbf{e}, \mathbf{f})$.

Besides the tensile and compression tests, the Young's modulus, as measure of stiffness, was also precisely analysed by ultrasonic testing due to its importance for implant design. Significant differences between both sample orientations could be found, summarized in 
Table 3. Samples built parallel to BD show a 18\% lower Young's modulus compared to the perpendicular direction which has a value of $194.8 \mathrm{GPa}$. Based on the crystallographic data collected by EBSD and the elastic single crystal constants reported by Music and Takahashi [51] for Fe-30Mn ( $\left.\mathrm{C}_{11}=169 \mathrm{GPa}, \mathrm{C}_{12}=109 \mathrm{GPa}, \mathrm{C}_{44}=136 \mathrm{GPa}\right)$ the Young's modulus for both sample directions was calculated by the Hill estimation approach [35]. The calculated values are in a good agreement with the measured one and demonstrate the high influence of the crystallographic texture on the elastic anisotropy. The reduced Young's modulus values parallel to $\mathrm{BD}$ can mostly be traced back to the low volume fraction of grains having $<111>$ orientations parallel to BD. For the fcc crystal structure of austenite, the highest Young's modulus values exist for the $<111>$ crystal directions and the lowest for the $<001>$ crystal directions. These values can be calculated from the single crystal elastic constants and are $\mathrm{E}_{<111>}=303 \mathrm{GPa}$ and $\mathrm{E}_{<001>}=101 \mathrm{GPa}$ for Fe-30Mn [35,51]

Table 3. Young's modulus of LPBF samples oriented parallel and perpendicular to BD, determined by the ultrasonic technique and Hill average calculated from EBSD texture data.

\begin{tabular}{ccc}
\hline & $\begin{array}{c}\text { Experimental } \\
\text { Young's Modulus E } \\
\text { in GPa }\end{array}$ & $\begin{array}{c}\text { Hill Average of } \\
\text { Young's Modulus E } \\
\text { in GPa }\end{array}$ \\
\hline Parallel to BD & $165.5 \pm 2.7$ & 175.6 \\
Perpendicular to BD & $194.8 \pm 0.9$ & 190.9 \\
\hline
\end{tabular}

\subsection{Corrosion Properties}

For corrosion testing in a simulated body fluid c-SBF, disc samples taken from cylindrical alloy specimens were used with the electrode area perpendicular (X-Y plane) or parallel (Y-BD plane) to the BD (Figure 1).

In Figure 6 representative OCP transients (Figure 6a) and subsequently recorded potentiodynamic polarization curves (Figure 6 b) are shown. The extracted corrosion parameter values are collected in Table 4 . Shortly after immersion of the rotating samples in the electrolyte the OCP dropped rapidly. This was followed by a steep rise and then, the OCP decreased continuously until it reached a steady state value of around $-600 \mathrm{mV}$ vs. SCE after $1 \mathrm{~h}$. This initial OCP behaviour is very similar for both analysed samples and is indicative for rapidly changing electrode surface states directly after exposure to the c-SBF solution. It may be ascribed to the pre-conditioning (re-passivation after grinding, rinsing, air exposure) of the electrode surfaces prior to the test and an initial preferred release of most reactive Mn-species from near-surface regions leading to a relative enrichment of more noble Fe species. When certain concentration ratios of the constituents are reached the electrode surface state transfers into a slightly less noble steady state.

Table 4. Overview of values from potentiodynamic polarization measurements of the sample surfaces prepared parallel and perpendicular to the BD. The current density $\left(\mathrm{i}_{\text {corr }}\right)$ values of the perpendicular to BD samples are in accordance to a former study [33]. OCP: Open circuit potential.

\begin{tabular}{cccc}
\hline & OCP $\mathbf{( 1 ~ h ) ~ i n ~} \mathbf{V}$ & $\mathbf{E}_{\text {corr }}$ in $\mathbf{~}$ & $\mathbf{i}_{\text {corr }}$ in $\boldsymbol{\mu} \mathbf{A} / \mathbf{c m}^{2}$ \\
\hline Parallel to BD (Y-BD) & $-0.590 \pm 0.002$ & $-0.548 \pm 0.004$ & $4.2 \pm 0.3$ \\
Perpendicular to BD (X-Y) & $-0.602 \pm 0.005$ & $-0.569 \pm 0.002$ & $3.6 \pm 0.3$ \\
\hline
\end{tabular}

In more detail, the $X-Y$ surfaces which are perpendicular to $B D$ showed typically a slightly more negative steady-state OCP value, i.e., by a few tens of milli-Volts, than those measured for Y-BD surfaces and therefore parallel to BD counterparts. This trend was also detectable for the $\mathrm{E}_{\mathrm{corr}}$ values which were determined from the potentiodynamic polarization curves. Whereas considering the standard deviations, the determined $i_{\text {corr }}$ values indicate similar corrosion rates for both analysed material directions. 
The more negative corrosion potential values for LPBF sample surfaces which are perpendicular to $\mathrm{BD}(\mathrm{X}-\mathrm{Y})$ are indicative for a slightly more reactive (corrosive) state. This may be due to superimposed effects of microstructure and defect density.

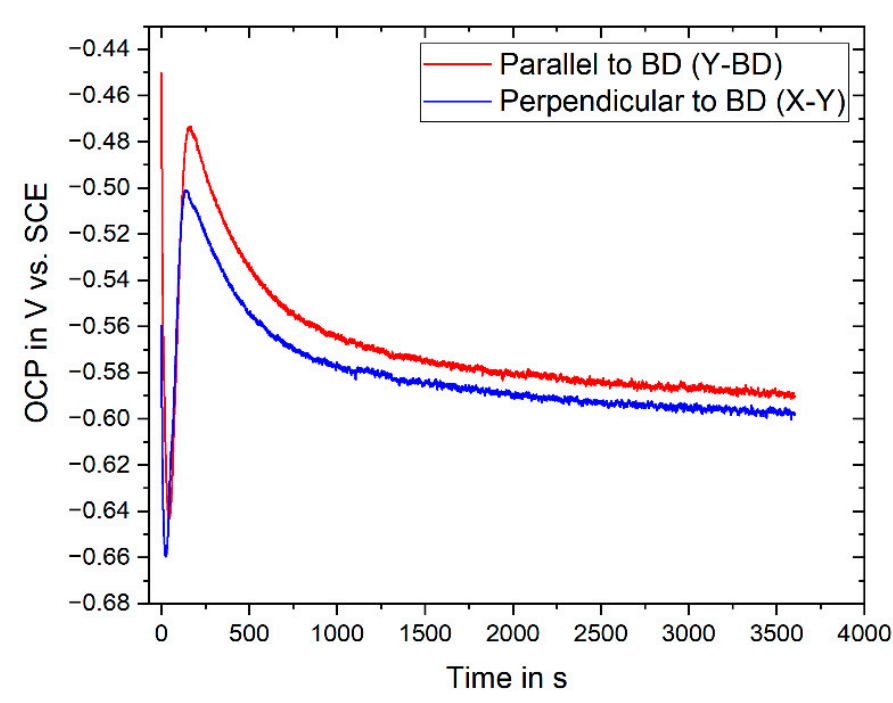

(a)

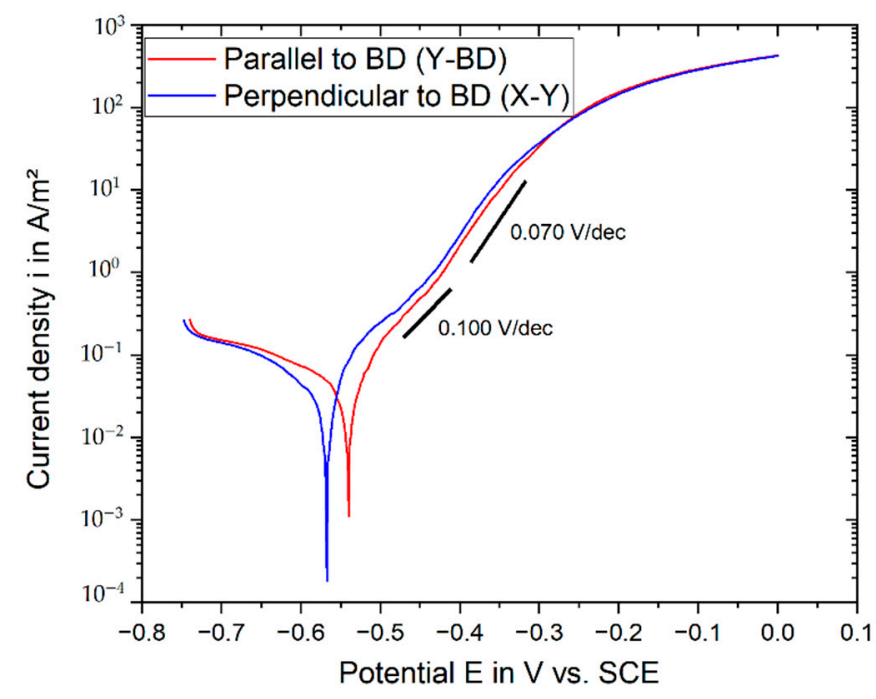

(b)

Figure 6. Potentiodynamic polarization measurements in corrected simulated body fluid of LPBF-processed FeMnCS with sample surfaces oriented parallel and perpendicular to BD with (a) the open circuit potential (OCP) for $1 \mathrm{~h}$ and (b) the corresponding Tafel diagrams.

According to the microstructure analysis of the single-phase austenitic FeMnCS alloy samples described in Section 3.1, the X-Y sample surface is characterized by a smaller mean grain size, i.e., only about half of that of the parallel to BD surface. Thus, the fraction of grain boundary regions is higher. This can favour corrosion processes because they represent higher energetic surface sites on the electrode area. Further, this sample surface has a weaker texture. i.e., has a more isotropic nature than the Y-BD surface. In addition the rarely occurring pores and binding defects might promote the corrosion in the first stages of corrosion [6].

The anodic curve branches of the FeMnCS alloy samples corresponding to enhanced active dissolution, i.e., the first $200 \mathrm{mV}$ of anodic polarization, exhibit two distinguished Tafel slopes. At low polarization this slope is about $0.100 \mathrm{~V} / \mathrm{dec}$, while a slope of about $0.070 \mathrm{~V} / \mathrm{dec}$ is derived at higher polarization.

This trend is in accordance with the description for active dissolution of pure Fe in chloride-containing solutions under different $\mathrm{pH}$ values where it is ascribed to a change in the complex reaction mechanism. At low polarization the Fe dissolution rate is controlled by chloride and hydroxide ions while at higher polarization only hydroxide ions accelerate the dissolution process [52]. In the present study for the new Fe-Mn-based alloy samples, absolute Tafel slope data are not comparable with those reported for Fe. This has to be ascribed to not identical experimental conditions and to the presence of a large reactive $\mathrm{Mn}$ fraction in the alloy superimposing the Fe dissolution reactions.

Moreover, under the applied anodic polarization conditions with accelerated active dissolution both FeMnCS alloy sample types exhibit a quite similar behaviour. The structural particularities resulting from the (electrode) surface orientation relative to the LPBF build direction are therefore not significant under more severe corrosion conditions. This was confirmed by additional SEM inspections of the electrode samples after the polarization tests (not shown here). However, much more in-depth corrosion damage analysis especially under application-relevant free corrosion conditions are needed and will be subject of future studies. 


\section{Conclusions}

The present work demonstrates the significant influence of different build directions realized by laser powder bed fusion on the microstructure and mechanical properties of a novel biodegradable Fe-30Mn-1C-0.02S alloy. From this study it could be shown that:

- The grains are elongated and show a preferred orientation of their $\{110\}$ planes along build direction. The measured texture was correlated with the significant difference of the Young's modulus parallel and perpendicular to build direction.

- The mechanical properties for the tensile test samples that were manufactured perpendicular to BD show higher strength and ductility values with a reduced scatter compared to parallel oriented specimens. This was mainly attributed to a less severe impact of inter-layer defects after fracture surface inspection. In compression testing, the variation especially parallel to BD was minimized due to the low impact of these defects. The remaining difference was attributed to the influence of texture.

- The corrosion behaviour that was derived from potentiodynamic polarization tests in c-SBF shows a slightly lower OCP and free corrosion potential of the perpendicular inspection plane and can be ascribed to a smaller grain size and to a low impact of the generated texture for this material and solution combination.

Future studies should focus on the influence of different LPBF scan parameters as well as post (heat) treatments on the evolving microstructure and its impact on the mechanical and degradation properties.

Author Contributions: M.O.: Conceptualization, writing—original draft preparation, visualization, mechanical and corrosion behaviour; S.P.: visualization, EBSD investigation, writing-review and editing; A.G.: writing—review and editing, methodology corrosion tests; U.K.: writing-review and editing; J.H.: Conceptualization, writing—original draft preparation, writing—review and editing, mechanical testing. All authors have read and agreed to the published version of the manuscript.

Funding: This research was funded by the German Research Foundation (DFG) under grant no. HU 2371/1-1 and project no. 277470500 and by Leibniz IFW Dresden. S. Pilz and A. Gebert acknowledge financial support by the German Research Foundation DFG under project GE 1106/12-1 no. 419952351.

Institutional Review Board Statement: Not applicable.

Informed Consent Statement: Not applicable.

Data Availability Statement: Data is contained within the article.

Acknowledgments: The authors would like thank Fabian Kochta, Jan Sander, Andrea Voß for technical support and the Open Access Fund of the Leibniz Association for funding the publication of this article.

Conflicts of Interest: The authors declare no conflict of interest.

\section{References}

1. Zadpoor, A.A.; Malda, J. Additive manufacturing of biomaterials, tissues, and organs. Ann. Biomed. Eng. 2017, 45, 1-11. [CrossRef]

2. Murr, L.E.; Gaytan, S.M.; Martinez, E.; Medina, F.; Wicker, R.B. Next generation orthopaedic implants by additive manufacturing using electron beam melting. Int. J. Biomater. 2012, 2012. [CrossRef] [PubMed]

3. Sing, S.L.; An, J.; Yeong, W.Y.; Wiria, F.E. Laser and electron-beam powder-bed additive manufacturing of metallic implants: A review on processes, materials and designs. J. Orthop. Res. 2016, 34, 369-385. [CrossRef] [PubMed]

4. Tilton, M.; Lewis, G.S.; Bok Wee, H.; Armstrong, A.; Hast, M.W.; Manogharan, G. Additive manufacturing of fracture fixation implants: Design, material characterization, biomechanical modeling and experimentation. Addit. Manuf. $2020,33,101137$. [CrossRef]

5. Santecchia, E.; Mengucci, P.; Gatto, A.; Bassoli, E.; Denti, L.; Rutkowski, B.; Barucca, G. Laser powder bed fusion: Tailoring the microstructure of alloys for biomedical applications. Mater. Today Proc. 2019, 19, 24-32. [CrossRef]

6. Sander, G.; Tan, J.; Balan, P.; Gharbi, O.; Feenstra, D.R.; Singer, S.; Thomas, L.; Kelly, R.G.; Scully, J.R.; Birbilis, N. Corrosion of additively manufactured alloys: A review. Corrosion 2018, 74, 1318-1350. [CrossRef] 
7. Lindell, D.; Pettersson, R. Crystallographic effects in corrosion of austenitic stainless steel 316L. Mater. Corros. 2015, 66, 727-732. [CrossRef]

8. Dong, S.; Chen, X.; La Plante, E.C.; Gussev, M.; Leonard, K.; Sant, G. Elucidating the grain-orientation dependent corrosion rates of austenitic stainless steels. Mater. Des. 2020, 191, 108583. [CrossRef]

9. Ralston, K.D.; Fabijanic, D.; Birbilis, N. Effect of grain size on corrosion of high purity aluminium. Electrochim. Acta 2011, 56, 1729-1736. [CrossRef]

10. Chlebus, E.; Kuźnicka, B.; Kurzynowski, T.; Dybała, B. Microstructure and mechanical behaviour of Ti-6Al-7Nb alloy produced by selective laser melting. Mater. Charact. 2011, 62, 488-495. [CrossRef]

11. Takaichi, A.; Nakamoto, T.; Joko, N.; Nomura, N.; Tsutsumi, Y.; Migita, S.; Doi, H.; Kurosu, S.; Chiba, A.; Wakabayashi, N.; et al. Microstructures and mechanical properties of $\mathrm{Co}-29 \mathrm{Cr}-6 \mathrm{Mo}$ alloy fabricated by selective laser melting process for dental applications. J. Mech. Behav. Biomed. Mater. 2013, 21, 67-76. [CrossRef]

12. Yap, C.Y.; Chua, C.K.; Dong, Z.; Liu, Z.H.; Zhang, D.Q.; Loh, L.E.; Sing, S.L. Sing, Review of selective laser melting: Materials and applications. Appl. Phys. Rev. 2015, 2, 041101. [CrossRef]

13. Zhang, L.-C.; Attar, H. Attar, selective laser melting of titanium alloys and titanium matrix composites for biomedical applications: A review. Adv. Eng. Mater. 2016, 18, 463-475. [CrossRef]

14. Bajaj, P.; Hariharan, A.; Kini, A.; Kürnsteiner, P.; Raabe, D.; Jägle, E. Steels in additive manufacturing: A review of their microstructure and properties. Mater. Sci. Eng. A 2020, 772, 138633. [CrossRef]

15. Carluccio, D.; Demir, A.G.; Bermingham, M.J.; Dargusch, M.S. Challenges and opportunities in the selective laser melting of biodegradable metals for load-bearing bone scaffold applications. Met. Mater. Trans. A 2020, 51, 3311-3334. [CrossRef]

16. Pruncu, C.I.; Hopper, C.; Hooper, P.A.; Tan, Z.; Zhu, H.; Lin, J.; Jiang, J. Study of the effects of hot forging on the additively manufactured stainless steel preforms. J. Manuf. Process. 2020, 57, 668-676. [CrossRef]

17. Haghdadi, N.; Laleh, M.; Moyle, M.; Primig, S. Additive manufacturing of steels: A review of achievements and challenges. J. Mater. Sci. 2020, 56, 64-107. [CrossRef]

18. Jahadakbar, A.; Nematollahi, M.; Safaei, K.; Bayati, P.; Giri, G.; Dabbaghi, H.; Dean, D.; Elahinia, M. Design, modeling, additive manufacturing, and polishing of stiffness-modulated porous nitinol bone fixation plates followed by thermomechanical and composition analysis. Metals 2020, 10, 151. [CrossRef]

19. Jafary-Zadeh, M.; Kumar, G.P.; Branicio, P.S.; Seifi, M.; Lewandowski, J.J.; Cui, F. A critical review on metallic glasses as structural materials for cardiovascular stent applications. J. Funct. Biomater. 2018, 9, 19. [CrossRef] [PubMed]

20. Zheng, Y.; Gu, X.; Witte, F. Biodegradable metals. Mater. Sci. Eng. R Rep. 2014, 77, 1-34. [CrossRef]

21. Shuai, C.; Liu, L.; Zhao, M.; Feng, P.; Yang, Y.; Guo, W.; Gao, C.; Yuan, F. Microstructure, biodegradation, antibacterial and mechanical properties of ZK60-Cu alloys prepared by selective laser melting technique. J. Mater. Sci. Technol. 2018, 34, 1944-1952. [CrossRef]

22. Schinhammer, M.; Hänzi, A.C.; Löffler, J.F.; Uggowitzer, P.J. Design strategy for biodegradable Fe-based alloys for medical applications. Acta Biomater. 2010, 6, 1705-1713. [CrossRef]

23. Hermawan, H.; Purnama, A.; Dube, D.; Couet, J.; Mantovani, D. Fe-Mn alloys for metallic biodegradable stents: Degradation and cell viability studies. Acta Biomater. 2010, 6, 1852-1860. [CrossRef]

24. Francis, A.; Yang, Y.; Virtanen, S.; Boccaccini, A.R. Iron and iron-based alloys for temporary cardiovascular applications. J. Mater. Sci. Mater. Med. 2015, 26, 138. [CrossRef] [PubMed]

25. Mouzou, E.; Paternoster, C.; Tolouei, R.; Purnama, A.; Chevallier, P.; Dubé, D.; Prima, F.; Mantovani, D. In vitro degradation behavior of Fe-20Mn-1.2C alloy in three different pseudo-physiological solutions. Mater. Sci. Eng. C 2016, 61, 564-573. [CrossRef]

26. Hufenbach, J.; Wendrock, H.; Kochta, F.; Kühn, U.; Gebert, A. Novel biodegradable Fe-Mn-C-S alloy with superior mechanical and corrosion properties. Mater. Lett. 2017, 186, 330-333. [CrossRef]

27. Hufenbach, J.; Kochta, F.; Wendrock, H.; Vos, A.; Giebeler, L.; Oswald, S.; Pilz, S.; Kühn, U.; Lode, A.; Gelinsky, M.; et al. S and B microalloying of biodegradable Fe-30Mn-1C-Effects on microstructure, tensile properties, in vitro degradation and cytotoxicity. Mater. Des. 2018, 142, 22-35. [CrossRef]

28. Loffredo, S.; Paternoster, C.; Giguère, N.; Barucca, G.; Vedani, M.; Mantovani, D. The addition of silver affects the deformation mechanism of a twinning-induced plasticity steel: Potential for thinner degradable stents. Acta Biomater. 2019, 98, 103-113. [CrossRef]

29. Hitzler, L.; Hirsch, J.; Heine, B.; Merkel, M.; Hall, W.; Öchsner, A. On the anisotropic mechanical properties of selective laser-melted stainless steel. Materials 2017, 10, 1136. [CrossRef]

30. Ni, X.-Q.; Kong, D.-C.; Wen, Y.; Zhang, L.; Wu, W.-H.; He, B.-B.; Lu, L.; Zhu, D.-X. Anisotropy in mechanical properties and corrosion resistance of 316L stainless steel fabricated by selective laser melting. Int. J. Miner. Met. Mater. 2019, 26, 319-328. [CrossRef]

31. Charmi, A.; Falkenberg, R.; Ávila, L.; Mohr, G.; Sommer, K.; Ulbricht, A.; Sprengel, M.; Neumann, R.S.; Skrotzki, B.; Evans, A. Mechanical anisotropy of additively manufactured stainless steel 316L: An experimental and numerical study. Mater. Sci. Eng. A 2021, 799, 140154. [CrossRef]

32. Gebert, A.; Kochta, F.; Voß, A.; Oswald, S.; Fernandez-Barcia, M.; Kühn, U.; Hufenbach, J. Corrosion studies on Fe-30Mn-1C alloy in chloride-containing solutions with view to biomedical application. Mater. Corros. 2017, 69, 167-177. [CrossRef] 
33. Hufenbach, J.; Sander, J.; Kochta, F.; Pilz, S.; Voss, A.; Kühn, U.; Gebert, A. Effect of selective laser melting on microstructure, mechanical and corrosion properties of biodegradable FeMnCS for implant applications. Adv. Eng. Mater. 2020, 22. [CrossRef]

34. Bachmann, F.; Hielscher, R.; Schaeben, H. Texture analysis with MTEX- Free and open source software toolbox. Solid State Phenom. 2010, 160, 63-68. [CrossRef]

35. Mainprice, D.; Hielscher, R.; Schaeben, H. Calculating Anisotropic Physical Properties from Texture Data Using the MTEX Open-Source Package; Special Publications; Geological Society: London, UK, 2011; Volume 360, pp. 175-192. [CrossRef]

36. DIN-Normenausschuss Materialprüfung, DIN 50125:2016-12: Testing of Metallic Materials-Tensile Test Pieces. 2016, pp. 1-17. Available online: https:/ / www.beuth.de/en/standard/din-50125/262241217 (accessed on 3 June 2021).

37. Kokubo, T.; Takadama, H. How useful is SBF in predicting in vivo bone bioactivity? Biomaterials 2006, 27, 2907-2915. [CrossRef] [PubMed]

38. Köhnen, P.; Létang, M.; Voshage, M.; Schleifenbaum, J.H.; Haase, C. Understanding the process-microstructure correlations for tailoring the mechanical properties of L-PBF produced austenitic advanced high strength steel. Addit. Manuf. $2019,30,100914$. [CrossRef]

39. Asta, M.; Beckermann, C.; Karma, A.; Kurz, W.; Napolitano, R.; Plapp, M.; Purdy, G.; Rappaz, M.; Trivedi, R. Solidification microstructures and solid-state parallels: Recent developments, future directions. Acta Mater. 2009, 57, 941-971. [CrossRef]

40. Zhou, X.; Li, K.; Zhang, D.; Liu, X.; Ma, J.; Liu, W.; Shen, Z. Textures formed in a CoCrMo alloy by selective laser melting. J. Alloy. Compd. 2015, 631, 153-164. [CrossRef]

41. Sun, Z.; Tan, X.; Tor, S.B.; Chua, C.K. Simultaneously enhanced strength and ductility for 3D-printed stainless steel 316L by selective laser melting. NPG Asia Mater. 2018, 10, 127-136. [CrossRef]

42. Chan, L.; Weiland, H.; Cheong, S.; Rohrer, G.; Rollett, A. The correlation between grain boundary character and lntergranular corrosion susceptibility of 2124 aluminum alloy. In Characterization and Modeling to Control Sintered Ceramic Microstructures and Properties; Rollett, A.D., Ed.; Wiley: Hoboken, NJ, USA, 2008; pp. 261-267.

43. Tsai, S.-P.; Konijnenberg, P.; Zaefferer, S.; Peter, N.; Gault, B.; Kawano-Miyata, K.; An, D.; Griffiths, T.A. Correlative microscopy observation (3D EBSD + APT + TEM) on intergranular corrosion behaviors in 316L stainless steel. Microsc. Microanal. 2019, 25, 748-749. [CrossRef]

44. Bouaziz, O.; Allain, S.; Scott, C.; Cugy, P.; Barbier, D. High manganese austenitic twinning induced plasticity steels: A review of the microstructure properties relationships. Curr. Opin. Solid State Mater. Sci. 2011, 15, 141-168. [CrossRef]

45. Koyama, M.; Sawaguchi, T.; Tsuzaki, K. Overview of dynamic strain aging and associated phenomena in Fe-Mn-C austenitic steels. ISIJ Int. 2018, 58, 1383-1395. [CrossRef]

46. Tang, M.; Pistorius, P.C.; Beuth, J.L. Prediction of lack-of-fusion porosity for powder bed fusion. Addit. Manuf. 2017, 14, 39-48. [CrossRef]

47. Tammas-Williams, S.; Zhao, H.; Léonard, F.; Derguti, F.; Todd, I.; Prangnell, P. XCT analysis of the influence of melt strategies on defect population in Ti-6Al-4V components manufactured by Selective Electron Beam Melting. Mater. Charact. 2015, 102 , 47-61. [CrossRef]

48. Shipley, H.; McDonnell, D.; Culleton, M.; Coull, R.; Lupoi, R.; O’Donnell, G.; Trimble, D. Optimisation of process parameters to address fundamental challenges during selective laser melting of Ti-6Al-4V: A review. Int. J. Adv. Manuf. Technol. 2020, 108, 769-783. [CrossRef]

49. Röttger, A.; Boes, J.; Theisen, W.; Thiele, M.; Esen, C.; Edelmann, A.; Hellmann, R. Microstructure and mechanical properties of 316L austenitic stainless steel processed by different SLM devices. Int. J. Adv. Manuf. Technol. 2020, 108, 769-783. [CrossRef]

50. Deev, A.; Kuznetcov, P.; Petrov, S. Anisotropy of mechanical properties and its correlation with the structure of the stainless steel 316L produced by the SLM method. Phys. Procedia 2016, 83, 789-796. [CrossRef]

51. Music, D.; Takahashi, T.; Vitos, L.; Asker, C.; Abrikosov, I.A.; Schneider, J.M. Elastic properties of Fe-Mn random alloys studied by ab initio calculations. Appl. Phys. Lett. 2007, 91, 191904. [CrossRef]

52. Macfarlane, D.R.; Smedley, S.I. The dissolution mechanism of iron in chloride solutions. J. Electrochem. Soc. 1986, 133, 2240-2244. [CrossRef] 